\title{
Construction of The Arabic Phonological Short Term Memory Test on Egyptian Children
}

\author{
Hedia M. El Neshwey, Mohammed A. Baraka, Nahla A. Rifaie, Amal S. Saber, Sally A. Sarwat \\ ENT Department, Phoniatric Unit, Faculty of Medicine, Ain Shams University, Cairo, Egypt. \\ Correspondence to Hedia M. El-Neshwey, Tel: 01003819318, Email: Hediaserry@med.asu.edu.eg.
}

\begin{abstract}
Background: Phonological short-term memory is a part of working memory, as working memory consists of four components: the central executive, the phonological loop, the visuo-spatial sketchpad and the episodic buffer.

Aim of the work: To construct a valid and reliable test for assessment of phonological short-term memory, which can be applied in language child disorders as on specific language impaired children. This might help to clarify more points in their diagnosis and therefore to guide a better management.

Subjects and methods: The subjects of the study were 2 groups: The first group consisted of 102 normal children between the ages of 4 to 8 years old, with average number of 25 children in each with 1 year age range. The second group included 31 specific language impaired children that were selected to match the control group as regard age and IQ level. The constructed test items were 17 in number. The test included the following items: digit span, syllable repetition ( for 1,2,3,4 syllables ), non sense word repetition (NSWR) of (1,2,3 and 4 syllables),dissimilar word set recall (short word set recall of 1 and 2 syllables, long word set recall of 3 and 4 syllables) and lastly similar word set recall (of 1,2,3 and 4 syllables).

Results: Reliability of the test was measured by test re-test, alpha Cronbach and split half method. Validity of the test was also measured using internal consistency, contrasted group validity and factorial validity.

Conclusion: The constructed test for measuring phonological short-term memory (PSTM) showed high reliability and validity and could be used on Arabic speaking children from 4 years to 8 years of age.
\end{abstract}

Keywords: Phonological short-term memory, Working memory, Non word- repetition digit span, SLI.

\section{INTRODUCTION}

Phonological short term memory (PSTM) is a part of working memory. Working memory consists of four components: the central executive, the phonological loop, the visuo-spatial sketchpad and the episodic buffer ${ }^{(\mathbf{1})}$.

It is a system that is involved in several cognitive abilities, including reasoning, learning, and comprehension. Working memory is important, because it provides a system for us to attend to important incoming sensory information and work on this incoming information by associating it with prior knowledge ${ }^{(2)}$.

Different synonyms for the phonological short- term memory are present. Some researchers call it "verbal short term memory", others call it "phonological short-term memory" or the "phonological loop". PSTM is a limited capacity storage system for the auditory or phonological information without manipulation. It has two distinct subcomponents: A short-term store and an articulatory rehearsal component. The phonological short-term memory is affected by phonological similarity, the word length effect and lexicality effect. PSTM can be assessed using tasks such as digit span, word span (word set recall) and non-word repetition (3). Specifically, measures such as digit span and non- word repetition correlate significantly with phonological short-term memory ${ }^{(3) .}$

Non-word repetition tasks are interpreted as a measure of PSTM because in order to accurately repeat the non-word several moments after it is presented, one must temporarily maintain the novel sound sequence in the phonological loop ${ }^{(3)}$. The previous tests done to measure the PSTM used mainly the Non-word Repetition Test (NWRT). The studies of non-word repetition have employed a variety of non-word stimuli. However, two sets of non-word stimuli have been used most frequently. The first is the set of 40 non-words developed by Gathercole and Baddeley ${ }^{(4)}$ and later revised to form the Children's Test of Non-word Repetition ${ }^{(5)}$. The second is the set of 16 non-words developed by Dollaghan and Campbell ${ }^{(6)}$, currently referred to as the Non-word Repetition Test (NWRT).

In addition, the tests were done for nonArabic speaking children except for the one that measures PSTM as a part from a battery that measures the whole working memory done by $\mathbf{E L}$ Desouky et al. ${ }^{(7)}$. The aim of this study was to develop a test for measuring PSTM, for Arabic speaking children between the ages of 4 to 8 years of age, in order to be used in related communicative disorders that show deficit in the PSTM as SLI disorder. 


\section{SUBJECTS AND METHODS}

Standardization group: consisted of 102 normal children between the ages of 4 years to 8 years old; Age group I (31 children) between 4 years--4years and 11 months old. age group II ( 22 children) between 5 years ---5yrs and 11 months old. Age group III (19 children) between 6 years ---6 years and 11 months old. Age group IV (30 children) between 7 years---7 years and 11 months old. They were selected from the normal children attending with their relatives at Phoniatrics Unit of Ain Shams University Hospitals. Also, they were selected at near-by nurseries and schools at Misr ElGededa and Nasr City.

Inclusion criteria for the first group: children who participated in the study showed: Normal language development for age using Arabic language test ${ }^{(8)}$. No history of speech problem. Average intelligence quotient (i.e IQ 90) or above by Stanford Binnet Intelligence scale " 4 th Arabic version ${ }^{(9)}$. Normal hearing subjectively.

The contrasted group included 31 specific language impaired children. They were selected to match the control group as regard age and IQ level. SLI group were chosen from patients attending Phoniatrics Unit of Ain Shams University Hospitals.

Inclusion criteria for the second group: Neurologically free from any deficit sensory or motor that could affect the speech or non-speech movements of the articulators. Normal hearing subjectively. Average intelligence quotient (i.e IQ 90) or above by Stanford Binnet Intelligence scale " $4^{\text {th }}$ Arabic version ${ }^{(9)}$. Clinical history of significantly delayed language development. Deficient language performance (more than 1.5 standard deviations (SD) below the mean value expected for chronological age) on the Arabic Language test ${ }^{(8)}$.

The test items were 17 in number. The test included the following items: Digit span: It contained 4 series, the number of digits in the initial series is two digits (from no.1-9) then increases by 1 in each successive series up to 5 digits.

Syllable repetition ( for 1,2,3,4 syllables ): It contained 16 syllables, $4 \mathrm{cv}$ monosyllabic structured, 4 bisyllabic $\mathrm{cv}$ structured series (i.e cvev), 4 trisyllabic cv structured series (i.e cvevev) and 4 tetrasyllabic cv structured series (i.e cvcvevcv).

Consonants used were one of the six consonants, which were $/ \mathrm{b} /, / \mathrm{d} /, / \mathrm{m} /, / \mathrm{n} /, / \mathrm{k} /$ and $/ \mathrm{g} /$ while the vowels used were /e/, /ae/, /a/, /i/ and /u/.
The child was asked to repeat each syllable, (beginning with monosyllables first), immediately after hearing it,only once not repeated, given one score if repeated it correctly and a zero score if not, so total score for this subtest will be 16 .

NSWR: It contains 40 non-sense words, ranging in difficulty from monosyllabic (10 in number), bisyllabic (10 in number), trisyllabic (10 in number), and multisyllabic words (i.e. 4 syllables, also 10 in number).

First, monosyllabic non-sense words were presented then increasing in difficulty till multisyllabic nonsense words.

The child was asked to repeat a made up funny words immediately after hearing it,only once not repeated, given one score if repeated it correctly and a zero score if not, so total score for this subtest will be 40 .

Dissimilar word set recall (short word set recall of 1 and 2 syllables, long word set recall of 3 and 4 syllables): are 4 series, the initial series has two words that increases by 1 in each successive series up to 5 words. Similar word set recall (of 1 , 2, 3 and 4 syllables) (i.e. using words of minimal and maximal pairs) were 4 series, the initial series contained two words that increased by 1 in each successive series up to 5 words. The child is asked to correctly repeat series of short, long and similar word set recall immediately after hearing the series in the same correct order and pronunciation as said by the examiner. He was given one score for each correct series said. For example if the child said the first two series from the digit series only he/she will take a score 2 out of 4 .

This study was conducted during (2015-2017) on normal children attending with their relatives at Phoniatrics Unit of Ain Shams University Hospitals, children were selected at near-by nurseries and schools at Misr ElGededa and Nasr City and the SLI group were chosen from patients attending Phoniatrics unit of Ain Shams University Hospitals. The study was approved by the Ethics Board of Ain Shams University and an informed written consent was taken from each participant in the study.

\section{Statistical analysis:}

Pearson's correlation: to test reliability of the test by (test re-test) method. Alpha Cronbach: test internal consistency of the items in order to assess the reliability of test. Split half (Guttmann's 
equation): to test reliability of the test. T-test for measuring: contrasted group validity. Factorial analysis: for measuring validity of the test. ANOVA and post hoc tests: to make comparisons between the different age groups performance.

\section{RESULTS}

Test reliability was measured by Test retest method performed on 30 children from the sample. These children were tested by the PSTMT and then re-evaluated by the same test after 2 weeks interval the results were shown in table (1).

Table (1): Results of test re-test method.

\begin{tabular}{|c|c|c|c|}
\hline $\begin{array}{c}\text { Pearson correlations } \\
\text { between raw scores } \\
\text { of }\end{array}$ & $\mathbf{R}$ & P value & Significance \\
\hline $\begin{array}{c}\text { Syllable repetition } \\
\text { total Score }\end{array}$ & $0.931^{* *}$ & 0.001 & HS \\
\hline $\begin{array}{c}\text { Non sense word } \\
\text { repetition total score }\end{array}$ & $0.941^{* *}$ & 0.001 & HS \\
\hline $\begin{array}{c}\text { Dissimilar word set } \\
\text { recall total score }\end{array}$ & $0.880^{* *}$ & 0.001 & HS \\
\hline $\begin{array}{c}\text { Similar word set recall } \\
\text { total score }\end{array}$ & $0.520^{* *}$ & 0.001 & HS \\
\hline Total score of PSTMT & $0.924^{* *}$ & 0.001 & HS \\
\hline
\end{tabular}

From the above table, correlation between the total scores of each test item for 1st and 2nd administration was statistically highly significant. In addition, the correlation between the whole test scores for the 1 st and 2nd administration was statistically highly significant, indicating that the test is highly reliable. Alpha Cronbach for testing reliability of the used tool PSTMT was very high 0.886 that indicated high test reliability. In addition, Guttman split half coefficient was 0.856 indicating high test reliability.

Test validity was measured by internal consistency, the internal structure of PSTMT was examined by making correlation between each subitem, each sub-item and its total score, and the total score of each item and the total score of the whole test as shown in tables (2-3-4-5-6).

Using Pearson's correlation, Correlation coefficients for internal consistency were (highly statistically significant), and this proves the strong internal consistency of the test.
Table (2): Correlation coefficients for internal consistency.

\begin{tabular}{|c|l|c|c|c|c|c|c|}
\hline \multicolumn{2}{|c|}{} & $\begin{array}{c}\text { PSTMT } \\
\text { Total }\end{array}$ & syllrep.Total & syllrep1 & syllrep2 & syllrep3 & syllrep4 \\
\hline \multirow{3}{*}{ syllrep1 } & r= & .159 & .147 & 1 & $-.054-$ & .059 & .116 \\
\cline { 2 - 8 } & P value & .067 & .091 & & .534 & .499 & .184 \\
\cline { 2 - 8 } & Significance & NS & NS & & NS & NS & NS \\
\hline \multirow{3}{*}{ syllrep2 } & r= & $.355^{* *}$ & $.478^{* *}$ & $-.054-$ & 1 & $.199^{*}$ & $.314^{* *}$ \\
\cline { 2 - 8 } & P value & .001 & .001 & .534 & & .021 & .001 \\
\cline { 2 - 8 } & Significance & HS & HS & NS & & S & HS \\
\hline \multirow{3}{*}{ syllrep3 } & r= & $.762^{* *}$ & $.798^{* *}$ & .059 & $.199^{*}$ & 1 & $.479^{* *}$ \\
\cline { 2 - 8 } & P value & .001 & .001 & .499 & .021 & & .001 \\
\cline { 2 - 8 } & Significance & HS & HS & NS & S & & HS \\
\hline \multirow{3}{*}{ syllrep4 } & r $=$ & $.671^{* *}$ & $.882^{* *}$ & .116 & $.314^{* *}$ & $.479^{* *}$ & 1 \\
\cline { 2 - 8 } & P value & .001 & .001 & .184 & .001 & .001 & \\
\cline { 2 - 9 } & Significance & HS & HS & NS & HS & HS & \\
\hline
\end{tabular}

Syllrep 1=syllable repetition monosyllable, syllrep $2=$ syllable repetition bisyllabic, syllrep $3=$ syllable repetition trisyllabic,syllrep $4=$ syllable repletion tetrasyllabic, NS=non-significant statistically,HS=highly significant statistically.

Table (3): Correlation coefficients for internal consistency.

\begin{tabular}{|c|l|c|c|c|c|c|c|}
\hline \multicolumn{2}{|c|}{} & $\begin{array}{c}\text { PSTMT } \\
\text { Total }\end{array}$ & nswr.Total & ns1syll & ns2syll & ns3syll & ns4syll \\
\hline \multirow{3}{*}{ ns1syll } & $\mathrm{r}=$ & $.420^{* *}$ & $.403^{* *}$ & 1 & $.319^{* *}$ & $.245^{* *}$ & $.288^{* *}$ \\
\cline { 2 - 9 } & P value & .001 & .001 & & .001 & .004 & .001 \\
\cline { 2 - 9 } & Significance & HS & HS & & HS & HS & HS \\
\hline \multirow{3}{*}{ ns2syll } & $\mathrm{r}=$ & $.720^{* *}$ & $.777^{* *}$ & $.319^{* *}$ & 1 & $.621^{* *}$ & $.569^{* *}$ \\
\cline { 2 - 9 } & P value & .001 & .001 & .001 & & .001 & .001 \\
\cline { 2 - 9 } & Significance & HS & HS & HS & & HS & HS \\
\hline \multirow{3}{*}{ ns3syll } & $\mathrm{r}=$ & $.855^{* *}$ & $.917^{* *}$ & $.245^{* *}$ & $.621^{* *}$ & 1 & $.779^{* *}$ \\
\cline { 2 - 9 } & Pvalue & .001 & .001 & .004 & .001 & & .001 \\
\cline { 2 - 9 } & Significance & HS & HS & HS & HS & & HS \\
\hline \multirow{3}{*}{ ns4syll } & r= & $.869^{* *}$ & $.918^{* *}$ & $.288^{* *}$ & $.569^{* *}$ & $.779^{* *}$ & 1 \\
\cline { 2 - 9 } & Pvalue & .001 & .001 & .001 & .001 & .001 & \\
\cline { 2 - 9 } & Significance & HS & HS & HS & HS & HS & \\
\hline
\end{tabular}

ns1syll:non-sense word repetition for 1 syllable, ns2syll:non-sense word repetition for 2syllables, ns3syll:non-sense word repetition for 3 syllables, ns4syll:non-sense word repetition for 4 syllables, HS: highly significant.

Table (4): Correlation coefficients for internal consistency.

\begin{tabular}{|c|c|c|c|c|c|c|c|}
\hline & & $\begin{array}{c}\text { PSTMT } \\
\text { Total } \\
\end{array}$ & swsr.Total & swsr1 & swsr2 & Iwsr3 & Iwsr4 \\
\hline \multirow[b]{2}{*}{ swsrl } & $r=$ & \begin{tabular}{|l|l|}
$.682 * *$ \\
\end{tabular} & $.827^{* * *}$ & 1 & $.543^{* * *}$ & $.582 * *$ & $.444 * *$ \\
\hline & \begin{tabular}{|l|} 
P value \\
Significance
\end{tabular} & $\begin{array}{l}.001 \\
\mathrm{HS} \\
\end{array}$ & $\begin{array}{l}.001 \\
\mathrm{HS}\end{array}$ & & $\begin{array}{l}.001 \\
\mathrm{HS}\end{array}$ & $\begin{array}{l}.001 \\
\mathrm{HS}\end{array}$ & $\begin{array}{l}.001 \\
\mathrm{HS}\end{array}$ \\
\hline \multirow[b]{3}{*}{ swsr2 } & & & & & & & \\
\hline & $\mathrm{r}=$ & $583^{* * *}$ & $.807^{* *}$ & $.543^{* * *}$ & 1 & $.527 * *$ & $.470^{* * *}$ \\
\hline & \begin{tabular}{|l} 
P value \\
Significance
\end{tabular} & $\begin{array}{l}.001 \\
\mathrm{HS}\end{array}$ & $\begin{array}{l}.001 \\
\mathrm{HS}\end{array}$ & $\begin{array}{l}.001 \\
\mathrm{HS}\end{array}$ & & $\begin{array}{l}.001 \\
\mathrm{HS}\end{array}$ & $\begin{array}{l}.001 \\
\mathrm{HS}\end{array}$ \\
\hline \multirow{3}{*}{ Lwsr3 } & $\mathrm{r}=$ & $.700^{* * *}$ & $.817^{* * *}$ & $.582^{* * *}$ & $.527^{* * *}$ & 1 & $.457 * *$ \\
\hline & \begin{tabular}{|l} 
P value \\
\end{tabular} & .001 & .001 & .001 & .001 & & .001 \\
\hline & Significance & $\mathrm{HS}$ & $\mathrm{HS}$ & $\mathrm{HS}$ & HS & & $\mathrm{HS}$ \\
\hline \multirow{3}{*}{ Lwsr4 } & $\mathrm{r}=$ & $.591^{* * *}$ & $.715^{* * *}$ & $.444^{* * *}$ & $.470^{* * *}$ & $.457 * *$ & 1 \\
\hline & Pvalue & .001 & .001 & .001 & .001 & .001 & \\
\hline & Significance & $\mathrm{HS}$ & $\mathrm{HS}$ & $\mathrm{HS}$ & $\mathrm{HS}$ & $\mathrm{HS}$ & \\
\hline
\end{tabular}


Table (5): Correlation coefficients for internal consistency.

\begin{tabular}{|c|c|c|c|c|c|c|c|}
\hline & & $\begin{array}{l}\begin{array}{c}\text { PSTMT } \\
\text { Total }\end{array} \\
\end{array}$ & simi.Total & simi1 & simi2 & simi3 & simi4 \\
\hline \multirow{3}{*}{ simil } & $\mathrm{E}=$ & $.702^{* * *}$ & $.827 * *$ & 1 & $.606 * *$ & $.413^{* * *}$ & $.474 * *$ \\
\hline & P value & .001 & .001 & & .001 & .001 & .001 \\
\hline & Significance & $\mathrm{HS}$ & $\mathrm{HS}$ & & $\mathrm{HS}$ & $\mathrm{HS}$ & $\mathrm{HS}$ \\
\hline \multirow{3}{*}{ simi2 } & $\mathrm{t}=$ & $.642^{* * *}$ & $.827 * *$ & $606 * *$ & 1 & $.439^{* * *}$ & $.513^{* * *}$ \\
\hline & \begin{tabular}{|l} 
Pvalue \\
\end{tabular} & .001 & .001 & .001 & & .001 & .001 \\
\hline & Significance & $\mathrm{HS}$ & $\mathrm{HS}$ & $\mathrm{HS}$ & & $\mathrm{HS}$ & $\mathrm{HS}$ \\
\hline \multirow{3}{*}{ simi3 } & $\mathrm{r}=$ & $.562^{* * *}$ & $.709 * *$ & $413^{* * *}$ & $.439 * *$ & 1 & $.435^{* *}$ \\
\hline & $P$ value & .001 & .001 & .001 & .001 & & .001 \\
\hline & \begin{tabular}{|l} 
Significance \\
\end{tabular} & $\mathrm{HS}$ & $\mathrm{HS}$ & HS & $\mathrm{HS}$ & & $\mathrm{HS}$ \\
\hline \multirow{3}{*}{ simi4 } & $\mathrm{E}=$ & $.699 * *$ & $.757 * *$ & $474 * *$ & $.513^{* * *}$ & $.435 * *$ & 1 \\
\hline & P value & .001 & $\begin{array}{l}.001 \\
\end{array}$ & .001 & .001 & .001 & \\
\hline & Significance & $\mathrm{HS}$ & $\mathrm{HS}$ & $\mathrm{HS}$ & $\mathrm{HS}$ & $\mathrm{HS}$ & \\
\hline \multicolumn{8}{|c|}{$\begin{array}{l}\text { Simil:similar word set recall for monosyllabic words,simi2: similar word set recall for } \\
\text { bisyllabic words, simiz: similar word set recall for trisyllabic words,simi4: similar word set } \\
\text { recall for tetrasyllabic words. HS: highly significant. }\end{array}$} \\
\hline
\end{tabular}

Table (6): Correlation coefficients for internal consistency.

\begin{tabular}{|c|c|c|c|c|c|c|}
\hline & & $\begin{array}{c}\text { PSTMT } \\
\text { Total }\end{array}$ & syllrep.Total & nswr.Total & disi.Total & simi.Tota \\
\hline \multirow{3}{*}{ PSTMT Total } & $R=$ & 1 & $.835 * *$ & $.941 * *$ & $.807 * *$ & $.834 * *$ \\
\hline & \begin{tabular}{|l|} 
P value \\
\end{tabular} & & .001 & .001 & .001 & .001 \\
\hline & Significance & & HS & HS & HS & HS \\
\hline \multirow{3}{*}{ yllrep.Total } & $R=$ & $.835^{* * *}$ & 1 & $.733^{* * *}$ & $.611^{* * *}$ & $.609^{* * *}$ \\
\hline & P value & .001 & & .001 & .001 & .001 \\
\hline & Significance & $\mathrm{HS}$ & & $\mathrm{HS}$ & $\mathrm{HS}$ & HS \\
\hline \multirow{3}{*}{ nswr.Total } & $R=$ & $.941^{* * *}$ & $.733 * *$ & 1 & $.619 * *$ & $.690 * *$ \\
\hline & $P$ value & .001 & .001 & & $\begin{array}{l}001 \\
.001\end{array}$ & .001 \\
\hline & Significance & $\mathrm{HS}$ & HS & & HS & HS \\
\hline \multirow{3}{*}{ disi.Total } & $R=$ & $.807 * *$ & $.611^{* * *}$ & $.619^{* * *}$ & 1 & $.728^{* * *}$ \\
\hline & \begin{tabular}{|l} 
P value \\
\end{tabular} & .001 & .001 & .001 & & .001 \\
\hline & Significance & $\mathrm{HS}$ & $\mathrm{HS}$ & $\mathrm{HS}$ & & HS \\
\hline \multirow{3}{*}{ simi.Total } & $\mathrm{R}=$ & $.834 * *$ & $.609 * *$ & $.690 * *$ & $.728 * *$ & 1 \\
\hline & P value & $\begin{array}{l}.001 \\
\end{array}$ & .001 & .001 & $\begin{array}{l}.001 \\
\end{array}$ & \\
\hline & Significance & HS & HS & HS & HS & \\
\hline
\end{tabular}

PSTMT total: phonological short term memory test total score, syllrep: syllable repetition total score, nswr total: non sense word repetition total score, disi. total: dissimilar word set recall total score, simi total: similar word set recall total score.

Contrasted group validity was done by making correlation between the normal group (no.102) and the SLI group (no.31) using Independent Samples t- Test as shown in table (7).

Table (7): Correlations between the normal group and SLI group.

\begin{tabular}{|c|c|c|c|c|c|c|c|}
\hline & \multicolumn{2}{|c|}{$\begin{array}{c}\text { Control group } \\
\text { No=102 } \\
\text { Mean +- SD }\end{array}$} & \multicolumn{2}{|c|}{$\begin{array}{c}\text { SLI group } \\
\text { No=31 } \\
\text { Mean +-SD }\end{array}$} & T & $\begin{array}{c}\text { P } \\
\text { value }\end{array}$ & Significance \\
\hline Digit span & 2.7 & $+\_0.63$ & 1.7 & $+\_0.7$ & 7.816 & 0.001 & HS \\
\hline $\begin{array}{c}\text { Syllable } \\
\text { repetition total } \\
\text { score }\end{array}$ & 13 &.+2 & 9.8 & $+\_1.6$ & 7.973 & 0.001 & HS \\
\hline $\begin{array}{c}\text { Non sense } \\
\text { syllable } \\
\text { repetition total } \\
\text { score }\end{array}$ & 32.8 & $+\_4.3$ & 21.7 & $+\_5.3$ & 11.701 & 0.001 & HS \\
\hline $\begin{array}{c}\text { Dissimilar } \\
\text { word set recall } \\
\text { total score }\end{array}$ & 8.7 & $+\_2.2$ & 5.9 & $+\_2$ & 6.294 & 0.001 & HS \\
\hline $\begin{array}{c}\text { Similar word } \\
\text { set recall total } \\
\text { score }\end{array}$ & 5.7 & $+\_2$ & 3.2 & $+\_2$ & 5.804 & 0.001 & HS \\
\hline $\begin{array}{c}\text { Total score of } \\
\text { PSTMT }\end{array}$ & 63 & $+\_9.1$ & 42.4 & $+\_9.9$ & 10.808 & 0.001 & HS \\
\hline
\end{tabular}

As shown in the above table there were statistically highly significant difference $(\mathrm{p}<0.001)$ between the control and SLI groups in all the test items total scores.

\section{Factorial validity}

Regarding factorial validity, correlation factors had been extracted for the test items and were analyzed using the principal component of Hotelling.

Table (8): Shows the extracted factors, their eigenvalue, $\%$ of variance and the cumulative $\%$.

\begin{tabular}{|c|c|c|c|}
\hline Component & Eigenvalue & \% of Variance & Cumulative \% \\
\hline 1 & 7.528 & 44.285 & \multirow{2}{*}{69.495} \\
\hline 2 & 1.326 & 7.802 & \\
\hline 3 & 1.219 & 7.173 & \\
\hline 4 & .959 & 5.644 & \\
\hline 5 & .781 & 4.591 & \\
\hline
\end{tabular}

Table (9): Shows the components (factors) and the loading of the test items upon them.

\begin{tabular}{|l|c|c|c|c|c|}
\hline \multirow{2}{*}{} & \multicolumn{5}{|c|}{ Component } \\
\cline { 2 - 6 } & $\mathbf{1}$ & $\mathbf{2}$ & $\mathbf{3}$ & $\mathbf{4}$ & $\mathbf{5}$ \\
\hline digitspan & .820 & $-.091-$ & $-.097-$ & .180 & .025 \\
syllrep1 & .141 & $-.622-$ & $-.095-$ & .652 & .280 \\
syllrep2 & .383 & .513 & .327 & .384 & $-.234-$ \\
syllrep3 & .753 & $-.172-$ & .287 & $-.206-$ & $-.052-$ \\
syllrep4 & .646 & $-.029-$ & .228 & .205 & $-.277-$ \\
ns1syll & .437 & .480 & .440 & .214 & .288 \\
ns2syll & .667 & $-.184-$ & .426 & $-.201-$ & $-.063-$ \\
ns3syll & .789 & $-.359-$ & .166 & $-.030-$ & $-.060-$ \\
ns4syll & .807 & $-.242-$ & .143 & $-.035-$ & .042 \\
swsr1 & .724 & .079 & $-.240-$ & .060 & $-.300-$ \\
swsr2 & .635 & .167 & $-.475-$ & .166 & $-.140-$ \\
swsr3 & .740 & .072 & $-.216-$ & .079 & $-.173-$ \\
swsr4 & .650 & .237 & $-.184-$ & $-.086-$ & .265 \\
simi1 & .734 & $-.055-$ & $-.210-$ & $-.161-$ & $-.076-$ \\
simi2 & .685 & .038 & $-.270-$ & $-.244-$ & .046 \\
simi3 & .616 & .290 & $-.197-$ & .036 & .418 \\
simi4 & .714 & $-.039-$ & .136 & $-.223-$ & .288 \\
\hline
\end{tabular}

\section{From the above table:}

1st factor: 16 items of the test (all test items except for syllable repetition for one syllable) have been significantly loaded upon it (greater than or equal to 0.3 ). Therefore, it had considered main factor, and accounted to $44.28 \%$ of the variance.

Degree of loading ranged from $0.383-0.820$.

2nd factor: 2 items were significantly loaded upon it (syllable repetition for 2 syllables and nonsense word repetition of 1 syllable). Degree of loading ranged from $0.480-0.513$, and it accounted for $7.80 \%$ of the variance.

The 3rd factor: 3 items were significantly loaded upon it (syllable repetition of 2 syllables, nonsense word repetition of 1 and 2 syllables). 
Degree of loading ranged from 0.3270.440 , and accounted for $7.71 \%$ of the variance.

The 4th factor: 2 items were significantly loaded upon it (syllable repetition of 1 and 2 syllables).

Degree of loading ranged from 0.3840.652 , and it accounted for $5.64 \%$ of the variance.

The 5th factor: 1 item was significantly loaded upon it (similar word repetition of 3 syllables).

Degree of loading was 0.418 , and it accounted for $4.59 \%$ of the variance.

Finally, Factorial validity proved that the test is highly valid to test the items it was designed for.

\section{DISCUSSION}

The previous tests done to measure the PSTM used only the NWR item. Those NWRT differ in their structure regarding : number of nonwords, articulatory complexity of non-words: simple ones containing single consonant vs. complex ones with consonant cluster, number of syllables within the non-words, word likeness and way of scoring. The studies of non-word repetition have employed a variety of non-word stimuli. However, two sets of non-word stimuli have been used most frequently. The first is the set developed by Gathercole and Baddeley ${ }^{(4)}$ of 40 non-words, 2-5 syllables, 20 singleton consonant and 20 with consonant clusters and later revised to form the Children's Test of Non-word Repetition ${ }^{(5)}$. The second is the set of 16 non-words developed by Dollaghan and Campbell ${ }^{(6)}$ currently referred to as the Non-word Repetition Test (NRT).

Our test was designed targeting age groups from 4-8 years old, as the association between nonword repetition (a pure index for measuring PSTM) and vocabulary knowledge is strongest at 4 years, declining to a non-significant level by 8 years ${ }^{(10)}$. Items included in the developed test were as follows: digit span and NWRT as they are considered pure index for measuring PSTM. Syllable repetition item was added to be used later in assessment of children with misarticulation to avoid constrain on their defected articulation. We also used the item of word set recall consisting of dissimilar and similar word set recall in order to measure the phonological similarity effect on PSTM. On the other hand, we used sets of words differing in length regarding number of syllables in words and the number of words in the sets in order to see the word length effect on PSTM. Regarding the number of syllables used in the test items: syllable repetition, NSWR and word set recall it ranged from monosyllable (easiest) till tetrasyllables (as in regular plural) which are frequent to be found in Arabic words.

As regards the digit span item: the child was asked to repeat digits in forward direction as it is the function of the phonological loop only, while backward direction measures the phonological working memory and it's done by both phonological loop and the central executive part of working memory altogether ${ }^{(11)} \cdot 1^{\text {st }}$ started with two digits spaced by one second, increased till reaching 5 digits. When the child was able to repeat five digits a trial for 6 digits was given but no one was able to do so, even at the a group age of 7-7 years and 11 months. Cowan (12) suggested that the "magical number" might not actually be $7 \pm 2$, as Miller suggested, but instead maybe much less $4 \pm$ 1. Also from Miller's formula the maximum digit span is $7 \pm 2$ that means it ranges from 5 digits to 9 digits ${ }^{(13)}$ which agrees with our study.

There was difference among the performance of the four age groups and it was statistically significant, that showed increase of digit memory span by the age.

As regards syllable repetition: this item was designed to be easier for the children with misarticulation ${ }^{(14)}$ (e.g to be used in SLI).

Consonants used were one of the six consonants, which are $/ \mathrm{b} /, / \mathrm{d} /, / \mathrm{m} /, / \mathrm{n} /, / \mathrm{k} /$ and $/ \mathrm{g} /$.

While the vowels used were /e/, /ae/,/a/,/i/ and $/ \mathrm{u} / . \mathrm{CV}$ syllable structure was used as it's the easiest and earliest to be aquired, as open syllables are the most frequent type of syllables used according to Kent and Bauer ${ }^{(15)}$.

Plossives and nasal sounds were chosen as they are the earliest to develop taking two back consonants and two anterior ones according to Saleh et $\boldsymbol{a l}^{(\mathbf{( 1 )}}$ who carried out a study designed to investigate the phonemic inventory and the phonological processes used by Arabic Egyptian children with Cairene dialect that revealed the following findings: Consonants showing high frequency of occurrence in age of two and half years are nasals $(/ \mathrm{m} /, / \mathrm{n} /)$ and plossives, but as regards $/ \mathrm{k} /$ phoneme it is acquired later according to Saleh $\boldsymbol{e t} \boldsymbol{a l}$. (16) but earlier according to Amayerh and Dayson ${ }^{(17)}$. 
Also, the above vowels were used in order to include nearly all the 6 Arabic vowels ${ }^{(18)}$.

Syllable repetition were 16 in number: four monosyllabic, 4 bisyllabic, 4 trisyllabic and four tetrasyllabic. The children between ages 4-6years and 11 months responded with $100 \%$ accuracy in the $1^{\text {st }}$ and $2^{\text {nd }}$ syllable repetition items. This may reveal that these test items were so easy for this age group as they were actually designed to test children with articulatory deficit.

Finally the scores for syllable repetition item showed increase in the span along with age.

As regards NSWR the syllable structure for the non-sense words were classified as follows according to Aquil $^{(\mathbf{1 9})}$ : light structure syllable CV, heavy structure CVC and CVV, super heavy structure CVCC and CVVC. All the Arabic consonants were considered to be included.

The four age groups responded with $100 \%$ accuracy in monosyllabic NSWR indicating the easiness for this item although the used syllable structure was CVC which is considered to be heavy and super heavy CVVC and CVCC.

It was found that mean scores for shorter NSW were greater than for longer ones which went with the word length effect. The more rapidly items can be articulated, the greater the span to be remembered. Also, the lengthier words take more time to repeat leading to shorter memory span ${ }^{(20)}$. Mean scores for NWRT were found increasing with the increase of age. This may be attributed to the developmental increase in the speed of articulation as found by Basho ${ }^{(20)}$.

As regards dissimilar word set recall, it was divided in to two parts: short word set recall and long word set recall. Word length effect was also present, with better mean scores for shorter words and also increase in PSTM span with age.

It was interesting to find that memory span in the same age group was nearly the same for words differing in number of syllables, which was against the word length effect. For example, age group I children were able to remember 3 monosyllabic word set recall, 3 bisyllabic word set recall and 3 trisyllabic word set recall, but it wasn't the case in the tetra syllabic word set recall as all age groups weren't able to remember more than a set of two tetrasyllabic words which may indicate difficulty of this item.
Regarding similar word set recall, mean scores were less than that of corresponding length in case of dissimilar word set recall ( number of syllables in the word and number of words inside the set). This went with phonological similarity effect, in which it was easier to store a list of words that are phonetically dissimilar, as storage is a phonological process which is a sound based dependent code. Also, recalling of similar words in a set, leads to phonological confusion during recall as found before by Basho ${ }^{(20)}$.

Finally, the total score for PSTM showed increase among the age groups. The test was also applied on 31 children with SLI with its different subtypes, and results were compared with the normal group.

SLI children were chosen as they have a specific deficit in the PSTM ${ }^{(21)}$. This finding came from the poor performance of the SLI children in non word repetition tasks ${ }^{(21)}$. It was found that the main gender of SLI children were male with 80.6 $\%$ (25 in number) and female children $19.4 \%$ (6 in number) that went with the prevalence of SLI which is more common in males, as estimated before by Stevenson and Richman ${ }^{(22)}$. Also, in the study by Tomblin et al. ${ }^{(23)}$, the prevalence estimate for boys was $8 \%$ and for girls $6 \%$.

When we applied the test on SLI children to measure the validity of the test, we found their performance was below the normal group regarding all the test items total scores : digit span total score, syllable repetition total score, NSWR total score, dissimilar word set recall total score and similar word set recall total score. Results of comparing performance of both groups gave high significance denoting high validity of the test. Also, it reflected that children with SLI had deficit in PSTM as proved before ${ }^{(21)}$.

As regards the lower scores for SLI children in NSWR : NSWR doesn't only tap PSTM but also the task taps multiple processes which are: speech perception (hearing), phonological decoding (segmenting the phonological string into smaller units), phonological memory, speech motor planning (assembling a motor plan that contains the relevant phonemes) and speech production (articulation). Thus, NWRT taps many abilities. Children with SLI exhibited problems with interpreting nonword repetition deficits, which therefore was problematic in those children as 
proved before by Vos ${ }^{(24)}$. SLI have more difficulty producing well-organized and stable rhythmic speech motor movements than typically developing children of the same age. This might provide one possible cause of the non-word repetition deficit ${ }^{(25)}$. Also, children with SLI had been reported to be differentially impaired in repeating non-words containing consonant clusters, which place greater demands on speech output processes due to the need to coordinate a variety of articulatory gestures within a syllable ${ }^{(25)}$. However, SLI group were able to get nearly same scores as the control group regarding syllable repetition item for one and two syllables but lower scores in case of three and four syllable repetition. As syllable repetition item was designed for misarticulated children using a light syllable structure $\mathrm{CV}$ with early acquired phonemes making it easy for them to articulate, but when the number of syllables increased to three and four syllables, it made a load on their memory resulting in their lower scores.

We could not conclude which subtype of SLI had more incidence for deficit in PSTM, as the whole SLI group was compared against the normal group due to their small number.

Because our developed PSTMT is considered a pioneer in the Arabic field, so we used different methods for measuring its reliabilty as Test re-test method, Alpha Cronbachs and Split half method. For measuring we used validity Internal consistency, Contrasted group validity and Factorial validity methods. All methods revealed high reliability and validity of the test as a measure for the intended item PSTM that it was designed for. Conclusion: the PSTMT is a valid and reliable tool that can be used to test the PSTM on Arabic speaking children between 4-8 years old.

\section{REFERENCES}

1. Nadler R, Archibald L (2014): The Assessment of Verbal and Visuospatial Working Memory with School Age Canadian Children. Canadian Journal of Speech, Language Pathology and Audiology, 38(3): 262-276.

2. Willis J, Mitchell G (2014): The neuroscience of learning: Principles and applications for educators. San Diego, CA: Bridge point Education.
3. Lee S and Gorman B (2012): Nonword repetition performance and related factors in children representing four linguistic group. International Journal of Bilingualism, 1(1): 1-17.

4. Gathercole S, Baddeley A (1990): Phonological memory deficits in language disordered children: Is there a causal connection? Journal of Memory and Language, 29(3): 336-360

5. Gathercole $\mathrm{S}$, Willis $\mathrm{C}$, Baddeley $\mathrm{A}$, Emslie H (1994): The Children's Test of Non-word Repetition: A test of phonological working memory. Journal of Memory and Language, 2: 103-127.

6. Dollaghan $\mathbf{C}$, Campbell $\mathbf{T}$ (1998): Nonword repetition and child language impairment. Journal of Speech, Language and Hearing Research, 41: 1136-1146.

7. El Desouky H, Shohdi S, Othman D, Abdel Hady A (2012): Assessment of working memory in normal Arabic speaking children. (Doctoral thesis). Faculty of Medicine, Cairo University.

8. Kotby MN, Khairy A, Baraka M, Rifaie N, El Shoubary A (1995): Language testing of Arabic speaking children. Proceedings of the XXIII World Congress of International Association of Logopedics and Phoniatrics. https:// www. karger. com/ Article/ Abstract/485656

9. Melika L (1998): Stanford Binnet Intelligence scale 4th (Arabic version). Second edition.Victor Kirolos publishing, Cairo.

10. Kornacki TE (2011): Measuring Phonological short Term Memory, a part from lexical knowledge. (Master's Dissertation). Department of Human Development and Applied Psychology. Ontario Institute for Studies in Education, University of Toronto. https:// tspace. library. utoronto. ca/. / 1/Kornacki_ Tamara_E_201111_MA_thesis. 
11. Park J, Ritter M, Lombardino L, Wiseheart R, Sherman S (2014): Phonological awareness intervention for verbal working memory skills in schoolage children with specific language impairment and concomitant word reading difficulties. International Journal of Research Studies in Language Learning, 3(4): 3-22.

12. Cowan $\mathbf{N}$ (2010): The magical mystery four how is working memory Capacity limited, and why? Current Directions in Psychological Science, 19(1): 51-57.

13. Gignac G (2015): The magical numbers 7 and 4 are resistant to the Flynn effect: No evidence for increases in forward or backward recall across 85. Intelligence, 48:85-95.

14. Shriberg L, Lohmeiera H, Campbell T, Dollaghanb $\mathrm{C}$, Greenc J, Moore $\mathrm{C}$ (2009): A Nonword Repetition Task for Speakers with Misarticulations: The Syllable Repetition Task (SRT). Journal of Speech, Language and Hearing Res., 52(5): 1189-1212.

15. Kent R, Bauer H (1985): Vocalizations of one-year-olds. Journal of Child Language, 13: 491-526.

16. Saleh M, Shoieb R, Hegazi M, Ali P (2007): Early Phonological Development in Arabic Egyptian Children: 12-30 Months. Folia phoniatrica et logopedica. DOI: $10.1159 / 000104461$

17. Amayreh MM, Dyson A (1988): The acquisition of Arabic consonants. Journal of Speech, Language and Hearing, 41: 642-653.

18. Kotby N, Saleh M, Hegazi M, Gamal N, Abdelsalam M, Nabil A, Fahmi S (2010): The Arabic Vowels: Features and Possible Clinical Application in Communication Disorders. Folia Phoniatrica and Logopaedica, 63:171-177.
19. Aquil R (2013): Arabic Syllable Structure though Different Phonological Theories. Journal of Modern Linguistics, 3(3): 259-267.

20. Basho S (2012): Relationship Between the Verbal Working Memory System and Subtypes of Reading Disability. (Ph. D dissertation). Department of Child Development, Tufts University.

21. Gibru D (2016): The Non-word Repetition Task as a clinical marker of Specific Language Impairment in Spanish-speaking children. Journal of First language. DOI: 10:1177/ 0142723715626069

22. Stevenson J, Richman N (1976): The prevalence of language delay in a population of three-year-old children and its association with general retardation. Developmental Medicine and Child Neurology, 18: 431-441.

23. Tomblin J B, Records, N L, Buckwalter PR, Zhang $X$, Smith E, O'Brien M (1997): Prevalence of specific language impairment in kindergarten children. Journal of Speech and Hearing Research, 40: 1245-1260.

24. Vos G (2012): The relationship between nonword repetition and word learning in children with SLI. (Master's thesis). Opleiding MSc Logopediewetenschap Clinical Language, Speech, and Hearing Sciences. Universiteit Utrecht. https://docplayer.nl/20151475-Universiteitutrecht-opleiding-msc-logoped.

25. Reuterskio“Id C, Grigos M I (2015): Nonword Repetition and Speech Motor Control in Children. BioMed Research International. Hindawi Publishing Corporation. 